\title{
Q Analysis of Mothers' Perspectives on Their Children with Developmental Disabilities: Communication Problems and Support Needs
}

\author{
Eun Jung Choi, Young Tae Kim, Min Kyung Kang, Hyun Jung Lee \\ Department of Communication Disorders, Ewha Womans University, Seoul, Korea
}

Correspondence: Young Tae Kim, PhD Department of Communication Disorders, Ewha Womans University, 52 Ewhayeodae-gil, Seodaemun-gu, Seoul 120-750, Korea

Tel: $+82-2-3277-2120$

Fax: +82-2-3277-2122

E-mail: youngtae@ewah.ac.kr

Received: January 5, 2014

Revised: February 15, 2014

Accepted: April 20, 2014

This article is based on a part of the first author's master's thesis from Ewha Womans University (2013).

This work was supported by the National Research Foundation of Korea Grant funded by the Korean Government (NRF-2012S1A5A2A03034254).

\begin{abstract}
Objectives:This study investigated the mothers' perspectives on their children with developmental disabilities, particularly focusing on their communication problems and support needs. Methods: Q-methodology was used, as it provides a method of analyzing the subjectivity of each item. Seventy-two items were obtained from a literature review and an open questionnaire. Item scores were generated from - 6 (least important) to 6 (most important). The collected data were analyzed using the QUANL PC program. Twenty-four participants (12 mothers of children with autism spectrum disorders and 12 mothers of children with intellectual disabilities) completed the Q-sort. Results: Three distinctive types were obtained: the title of type 1 is 'external communication', type 2 'internal analytic', and type 3 'media searching'. The derived types were discussed in terms of both mothers' perception on their children's communication problems and their support needs, which delineate the unique and/or shared common themes across the three types. Conclusion: The results of the present study identified three types of mothers of children with developmental disabilities. The study suggested some referential data that might be useful for speechlanguage therapists to apply a more systematic approach toward the parents and families of children with developmental disabilities.
\end{abstract}

Keywords: Children with development disabilities, Communication problem, Mother's perception, Q-methodology
발달장애아동의 언어 및 의사소통 어려움은 단순히 언어학적 결 함에만 기인하는 것이 아니라 사회적 결함 및 인지적 결함을 동반 하는 경우가 많다. 사회적 결함이나 인지적 결합이 있는 경우 의사 소통 능력에 어려움이 나타나며, 다른 사람을 이해하는 능력이 제 한되고, 언어의 사회적 측면에 제약을 가져와 결국 다른 사람들과 상호관계를 맺기가 어렵게 만든다. 따라서 발달장애아동의 언어문 제를 다룰 때는 언어와 밀접한 관계가 있는 사회적 및 인지적 결함 의 여부나 특성을 파악할 필요가 있다.

유아 특수교육의 초창기인 1960년대에는 장애아동을 위한 서비 스의 초점이 아동의 치료 및 교육에만 맞춰졌다. 그러나 아동 자체 에만 초점을 둔 교육은 기대했던 만큼의 효과를 거두지 못했으며, 전문가들은 이런 교육의 비효과성을 유아 개개인의 요구와 각각의 가족 상황을 고려하지 않은 교육의 결과로 인식하기 시작하였다
(Lee \& Kim, 2000). 이에 장애아동 가족을 교육의 중심에서 참여하 고 협력해야 하는 방향으로 전환하기 시작하였다. 가족이 장애아 에게 가장 강력하고 지속적인 영향을 준다는 것은 이미 선행연구 에서 밝혀진 바가 있다.

Bronfenbrenner (1977)의 생태학적 이론은 장애아동을 둘러싸 고 있는 주변 환경과 더불어 가족의 중요성을 인식시키게 되었다. 또한 가족이 어떤 외적 요인보다 아동의 발달에 많은 영향을 미치 게 되며(Robbins, Dunlap, \& Plienis, 1991), 아동의 성장발달과정 에서 가장 강력하고 폭넓은 영향력을 보일 수 있는 대상이라는 연 구(Hong et al., 2010) 등의 결과를 통해 장애아동 가족에 대한 지원 의 필요성이 크게 대두되게 되었고 사회적 관심 및 학문적 관심이 되었다. 장애아동의 가족은 아동과 가족의 상호순환적인 관계로 인해 그 중요성이 더욱 강조되는데, 예를 들어, 장애아동 가족 간의 
Eun Jung Choi, et al. • Q Analysis of Mothers' Perspectives on Their Children with Developmental Disabilities

관계는 일차적으로 아동의 장애로 인해 가족이 영향을 받으나 그 영향은 가족의 반응에 영향을 미치게 되고 순환적으로 다시 아동 에게 영향을 미치게 되어 아동의 교육과 발달에까지 영향을 주게 된다(O'Shea, 2001). 또한 가정은 의사소통을 통하여 자녀의 정서 및 사회화의 발달과 인성 형성에 지대한 영향을 미치며, 아동으로 하여금 사회화를 경험하게 하도록 하는 최초의 기관으로 가족 구 성원과의 인간관계를 촉진시키고 사회성을 발달시키는 매개체 역 할을 한다. 일반적으로 대부분의 아동에게 가족은 가장 친밀하고 중요한 삶의 일부이기 때문에, 가족 내에서 아동을 관찰하면 아동 의 전반적 현재 기능 수준과 더불어 향후 발달 가능성에 대해 예견 할 수 있다(Granlund, BjÖrck-ÅKesson, Wilder, \& Ylvén, 2008). 그 러나 의사소통에 어려움이 있는 대다수의 장애아동의 부모는 육 아 부담과 아동의 의사소통 문제로 인한 어려움이 가중되어 일반 부모들에 비해 훨씬 더 많은 스트레스를 경험하고(Lee, 2000), 이로 인해 장애아동과 가족구성원은 긍정적인 상호작용 발달에 어려움 을 겪게 된다. Kim, Lee, Kim, Kim과 Park (2005)의 연구에서 의사 소통에 문제가 있는 중도중복장애아동들의 어머니는 다른 가족 구성원의 욕구를 동시에 충족시켜야 하는 역할 수행도 해야 하므 로 더 많은 심리적 부담감을 경험한다고 보고하였다. 장애아동의 부모는 일반아동 부모에 비해서 많은 스트레스를 경험하게 되고 (Lee, Kang, \& Lee, 1999), 일반적인 양육비에 치료비를 추가로 부담 해야 하는 어려움과 양육에 따른 정신적, 신체적인 만성적 피로를 겪게 된다. 장애아동 가족이 갖게 되는 문제들에 대하여 다른 측면 에서 생각해 보면 그들이 갖고 있는 문제점 자체가 곧 그들이 누군 가에게 또는 우리사회나 국가로부터 해결 받기를 바라는 욕구가 될 수 있다. 한 가정에 장애아동이 출생하게 되면 가족 모두는 일반 적인 생활의 기능이 약화되거나 사회적인 생활이 원활하지 못하게 되고 가족구성원 각자 누군가의 도움을 필요로 하게 된다. 장애아 동의 어머니들이 필요로 하는 가족지원에 대한 욕구를 심층 면접 한 결과를 살펴보면, 장애자녀를 위한 적절한 교육기관, 재정적 지 원, 방학 중 혹은 방과후 프로그램, 아동 탁아 및 단기 보호 서비스, 장애아동 가족구성원의 문제 해결과 관련된 가족교육 및 상담, 가 사보조, 장애인에 대한 사회적 의식 개선 문제 등을 들 수 있다(Lee \& Kim, 2000).

의사소통 장애를 가진 발달장애아동을 지원하기 위해서는 아동 의 의사소통적 특성을 올바르게 파악한 후 일관적이고 체계적인 교육과 가정의 협조가 필요하며 특히 아동의 의사소통능력에 대한 모든 정보를 제공할 수 있고, 가장 근접한 곳에서 많은 시간을 접하 고 있는 가족의 역할을 강화하는 것이 중요하다. 또한 발달장애아 동의 가족을 지원하기 위해서는 현재와 가까운 미래 환경을 고려
하여 가족의 요구를 파악하고 목표를 선정하여 발달장애아동들의 가족을 위해 지원할 수 있는 프로그램을 고려해야 한다.

이처럼 장애아동 가족의 중요성이 대두됨에 따라 의사소통장애 아동을 대상으로 하는 연구를 벗어나 가족을 대상으로 하는 연구 도 많이 이루어지고 있다. 이 연구들은 대체로 많은 수의 대상자에 게 설문지를 이용하여 그들의 의견을 종합하는 설문조사방식을 이 용하거나(Jeon, Kang, \& Park, 2012; Lee, Kang, \& Kim, 2013), 또는 적은 수의 대상자에게 심층면접을 실시하여 공통된 의견을 도출해 내는 질적 연구방법을 이용하였다(Bae, 2009; Kim et al., 2005). 하 지만, 양적 연구방법의 경우 평균적인 집단의 특성을 예측하기엔 효과적이지만, 개개인의 특성과 주관성을 밝히기엔 무리가 있고 (Choi \& Lee, 2005), 특히, '요구'라는 것은 객관적인 자극이라기보 다는 개인의 평가가 중요하므로 지금까지와는 다른 각도의 연구의 필요성을 주장할 수 있다. 또한 질적 연구의 경우 극히 일부 대상자 를 중심으로 이루어지기 때문에 그 결과를 일반화하기 어렵다는 제한이 있다. 따라서, 본 연구에서는 의사소통장애를 가진 발달장 애아동의 의사소통 문제와 어머니의 요구에 대한 개별적이고 다양 한 견해를 수집하여 그 결과를 구체적이고, 심도 있게 분석하기에 는 양적 혹은 질적 조사만으로는 어려움이 있다는 선행연구의 제 언에 따라(Ha, 2010; Lee et al., 2013) 주관적 요인을 주요 변인으로 하는 대안적 연구방법인 Q-방법론으로 접근하는 연구를 실시하였 다. Q-방법론은 개인에게 내재되어있는 주관성 요인을 객관적인 방 법으로 측정하려고 시도하는 연구방법으로 $\mathrm{Q}$ 모집단 이론과 요인 분석 방법을 사용한다(Kim, 2008). Q-방법은 대상자들로 하여금 측정대상에 대한 태도나 의견을 대표하는 일련의 카드들을 미리 정해진 분포에 맞게 순서적으로 분류하여 주어진 카드의 값을 결 정하는 방법으로 연구자의 조작적 정의가 아닌 응답자 스스로가 그들의 의견과 의미를 만들어 가는 방법이다(Kim, 2008). 즉 전제 로부터 가설을 끌어내는 것이 아니라 가설을 발견하는 것으로 실 제 무엇이 발생하고 있는가 하는 것을 이해하고 발견하는데 매우 유용하다.

이에 본 연구에서는 Q-연구방법을 이용하여 발달장애 아동의 어머니들이 인식하는 자녀의 의사소통 문제와 지원 요구의 유형 및 특성에 관한 주관적 구조를 분석함으로써 현실적인 언어치료 지원 의 방향을 제안하고자 하였다.

본 연구의 연구문제는 다음과 같다.

첫째, 발달장애아동 어머니의 자녀 의사소통 문제 인식 및 지원 요구 유형은 어떠한가?

둘째, 발달장애아동 어머니의 자녀 의사소통 문제 인식 및 지원 요구 유형별 특성은 어떠한가? 


\section{연구 방법}

\section{Q표본의 구성}

본 연구의 Q모집단은 발달장애아동의 어머니가 인식하는 아동 의 의사소통문제 및 요구에 대한 진술문을 추출하기 위하여 관련 문헌 고찰과 설문조사를 통해 추출하였다. 질문지를 이용한 자료 의 수집은 서울 및 경기 지역의 병원 및 언어치료실에서 의사소통 장애문제로 인한 언어치료를 받고 있는 자녀를 둔 어머니 182명으 로부터 진술을 얻었다. 이 외에도 관련 선행 연구와 전문서적(예: Bishop, 1998; Kim, 2002; Oh, Lee, \& Kim, 2012)을 통해 얻은 자료 를 합하여 $\mathrm{Q}$ 모집단을 추출하였다.

$\mathrm{Q}$ 표본의 선정을 위하여 준비된 $\mathrm{Q}$ 모집단을 각각 어머니의 배경 정보, 현재 의사소통 문제, 의사소통 요구, 언어치료지원요구의 4 개 의 하위영역으로 나누어 정리하였고, 이를 여러 번 반복하여 읽으 면서 주제별로 공통적인 의미나 가치를 가진다고 생각되는 진술문 끼리 합쳐 범주화하였다. 최종적으로 범주화된 문항에 대해 다시 언어치료전문가 2 인의 검토와 수정 절차를 거쳐 최종 72 개의 $\mathrm{Q}$ 표 본을 선정하였다(Table 1).

\section{$\mathrm{P}$ 표본}

본 연구에서 $\mathrm{P}$ 표본은 자녀의 의사소통의 어려움에 대한 진술문 을 읽고 동의 여부를 평가해서 태도를 밝혀야 할 발달장애아동의 어머니들이다. 본 연구에서는 발달장애아동 중 의사소통장애를 가 지고 있으며, 서울·경기 지역에 위치한 병원 및 언어치료기관에서 언어치료를 받고 있는 아동을 둔 어머니 24 명(자폐성장애 12 명, 지 적장애 12 명)을 선정하였다.

\section{$\mathrm{Q}$ 분류 및 분석}

본 연구에서는 24 명의 $\mathrm{P}$ 표본에게 72 개의 $\mathrm{Q}$ 표본(진술문)을 인쇄
한 카드를 제공하여 전체적인 내용을 파악하게 한 후 동의(+), 중립 (0), 동의하지 않음(-)으로 분류시켰다. 그리고 대상자의 찬성 또는 반대의 정도에 따라 분포도의 모양대로 분류하도록 하였다. 이때 양극단 $(+6,+5,-6,-5)$ 에 위치한 진술문들에 대해서 선택 이유를 질 문하여 이를 기록하였다(Figure 1).

자료의 분석은 QUANL PC program을 이용하여 처리하였고, Q 요인분석은 주요인 분석(principal component factor analysis) 방법 을 이용하였다. 가장 이상적인 결정을 위해 eigenvalue 1.0 이상을 기준으로 요인수를 다양하게 입력시켜 산출된 결과 최선이라고 판 단된 유형을 선택하였으며, 적합한 문항을 선정하기 위해 표준점수 (Z-score)를 사용하였다.

\section{연구 결과}

\section{Q유형의 형성}

본 연구에서 발달장애아동 어머니의 자녀와의 의사소통 문제와 요구를 분석한 결과 세 가지의 유형으로 나타났다. 전체 연구대상

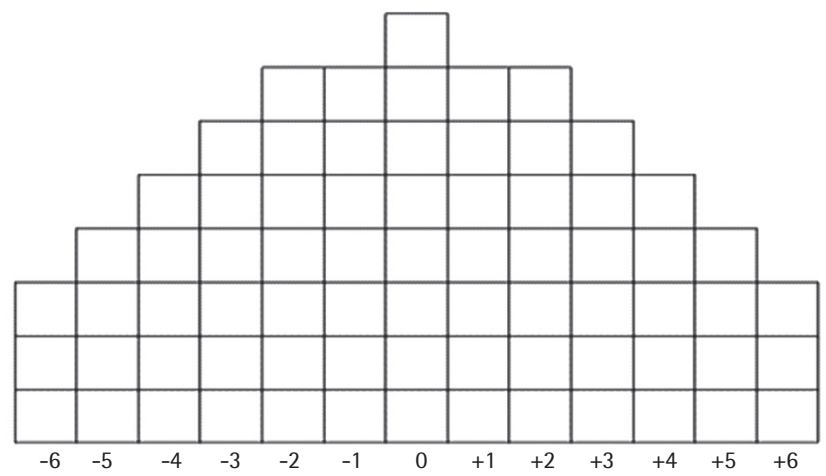

Figure 1. 0 Distribution (Q-sort item scores were generated ranging from -6 to 6 , anchoring the least important and the most important ends of the opinion continuum).

Table 1. Conceptual categories abstracted from 0 population

\begin{tabular}{ll}
\hline Q population & Conceptual category (item number) \\
\hline Background information & Emotion \& feeling (3) \\
Current communication problems & Language (vocabulary, syntax) problems (7) \\
Conversation \& discourse & Learning problems (4) \\
Communication functions & Discourse management \& communication \\
Nonverbal communication & Functions (6) \\
Communication needs & Characteristics of SLPS (4) \\
Improving child's communication skills & Institute types (3) \\
Improving child-family interaction skills & Interaction \& nonverbal communication (7) \\
Improving quality of life for children with communication problems and their families & Needs to SLPs (15) \\
Language therapy support needs & Parent training (2) \\
Additional media for language therapy & Media (5) \\
Parent training & Main complaint and needs (16) \\
\hline
\end{tabular}


Table 2. Characteristics of study participants

\begin{tabular}{|c|c|c|c|c|c|c|c|c|c|c|c|c|}
\hline \multirow{2}{*}{ Type } & \multirow{2}{*}{ Ranking } & \multirow{2}{*}{$\begin{array}{l}\text { Weighted } \\
\text { value }\end{array}$} & \multirow{2}{*}{ No. } & \multicolumn{3}{|c|}{ Mother } & \multicolumn{3}{|c|}{ Child } & \multirow{2}{*}{$\begin{array}{l}\text { Age diag- } \\
\text { nosed (mo) }\end{array}$} & \multirow{2}{*}{$\begin{array}{l}\text { Severity (moth- } \\
\text { er's perception) }\end{array}$} & \multirow{2}{*}{ Funding } \\
\hline & & & & Age (yr) & Occupation & Education & Age (yr) & Sex & Disability & & & \\
\hline \multirow[t]{12}{*}{1} & 1 & 2.09 & 16 & 36 & No & High school & 7 & $\mathrm{~F}$ & ID & 36 & Moderate & Insurance \\
\hline & 2 & 2.08 & 1 & 37 & No & High school & 8 & $M$ & ID & 28 & Mild & Work \\
\hline & 3 & 1.51 & 8 & 39 & Yes & High school & 7 & $\mathrm{~F}$ & ID & 48 & Moderate & Work \\
\hline & 4 & 1.48 & 17 & 33 & No & High school & 6 & $M$ & ID & 24 & Moderate & School \\
\hline & 5 & 1.38 & 9 & 37 & No & High school & 8 & $\mathrm{M}$ & ID & 36 & Mild & Insurance \\
\hline & 6 & 1.14 & 15 & 35 & No & High school & 8 & M & ID & 35 & Moderate & School \\
\hline & 7 & 1.10 & 7 & 40 & No & College & 9 & $\mathrm{~F}$ & ID & 32 & Moderate & Work \\
\hline & 8 & 1.08 & 23 & 34 & No & College & 6 & $\mathrm{~F}$ & ID & 36 & Moderate & Government \\
\hline & 9 & 1.06 & 18 & 39 & No & College & 6 & $M$ & ID & 28 & Moderate & Government \\
\hline & 10 & 0.99 & 2 & 34 & No & College & 6 & $M$ & ID & 32 & Moderate & Self-pay \\
\hline & 11 & 0.85 & 10 & 29 & No & High school & 6 & $\mathrm{M}$ & ID & 28 & Moderate & School \\
\hline & 12 & 0.66 & 6 & 36 & Yes & College & 6 & $\mathrm{M}$ & ASD & 36 & Mild & Self-pay \\
\hline \multirow[t]{8}{*}{2} & 1 & 4.23 & 12 & 38 & No & College & 9 & $M$ & ASD & 36 & Severe & Self-pay \\
\hline & 2 & 2.97 & 13 & 34 & No & High school & 8 & $\mathrm{~F}$ & ASD & 35 & Severe & School \\
\hline & 3 & 2.28 & 21 & 39 & No & College & 6 & $M$ & ASD & 32 & Severe & Self-pay \\
\hline & 4 & 1.58 & 5 & 33 & No & High school & 8 & $M$ & ASD & 34 & Severe & Government \\
\hline & 5 & 1.26 & 24 & 38 & No & College & 7 & $M$ & ID & 40 & Mild & Insurance \\
\hline & 6 & 1.11 & 19 & 39 & No & College & 9 & $\mathrm{M}$ & ASD & 32 & Severe & Self-pay \\
\hline & 7 & 0.99 & 14 & 34 & No & College & 6 & $\mathrm{M}$ & ASD & 42 & Severe & Self-pay \\
\hline & 8 & 0.58 & 3 & 34 & No & High school & 7 & $\mathrm{~F}$ & ASD & 38 & Moderate & School \\
\hline \multirow[t]{4}{*}{3} & 1 & 2.64 & 20 & 40 & No & College & 10 & $\mathrm{~F}$ & ASD & 48 & Mild & Work \\
\hline & 2 & 2.51 & 22 & 42 & No & High school & 6 & $M$ & ASD & 34 & Mild & Insurance \\
\hline & 3 & 1.64 & 4 & 38 & No & College & 9 & $M$ & ASD & 35 & Moderate & Work \\
\hline & 4 & 1.15 & 11 & 33 & No & College & 7 & $\mathrm{~F}$ & ASD & 32 & Mild & Self-pay \\
\hline
\end{tabular}

$\mathrm{ID}=$ intellectual disability; $\mathrm{ASD}=$ autism spectrum disorder.

Table 3. The results of correlation analysis

\begin{tabular}{lccc}
\hline & Type 1 & Type 2 & Type 3 \\
\hline Type 1 & - & - & - \\
Type 2 & -.38 & - & - \\
Type 3 & .27 & .01 & - \\
\hline
\end{tabular}

Type 1 = external communication; type 2 = internal analytic; type 3 = media searching

자 24 명 가운데 제 1 유형에 속한 사람은 12 명, 제 2 유형은 8 명, 제 3 유 형은 4 명으로 분류되었다(Table 2).

세 가지의 유형은 전체 변량의 $57.77 \%$ 를 설명하고 있는 것으로 나타났다. 각각의 유형 내에서 인자가중치(eigenvalue)가 높은 사람 일수록 그가 속한 유형에 있어서 그 유형을 대표할 수 있는 전형적 (prototype) 혹은 이상적(ideal)인 사람임을 나타낸다. 즉 특정 유형 에서 인자가중치수치가 높은 사람이 그 유형을 대표할 수 있는 이 상적인 사람이라는 뜻이다. 또한 유형 간의 상관관계는 각 유형간 의 유사성을 나타내는 것으로 Table 3 에 제시된 것과 같다. 제 1 유형 과 제 2 유형은 -.383 , 제 2 유형과 제 3 유형은 .011 , 제 1 유형과 제 3 유형 은 .267의 상관이 있었다. 유형간 상관이 극단적으로 높지 않으므 로 전반적으로 독립성을 유지하면서 각 유형에 속한 표본들을 잘 대표해 주고 있다고 볼 수 있다.

\section{유형별 특성}

\section{제1유형: 외적 소통형}

제 1 유형으로 분류된 참가자는 12 명으로, 인구사회학적 특성은 Table 2 과 같다. 제 1 유형으로 분류된 참가자의 아동의 진단명은 지 적장애 11 명, 자폐성아동 1 명이었으며, 그들은 아동의 장애수준이 보통 또는 가벼운 편이라고 응답하였다.

제 1 유형이 크게 동의하거나 부정하는 진술문과 그 비중을 제시 하면 Table 4 와 같다. 제 1 유형에 속한 참가자들은 '내 아이의 언어 문제에 대해 주위 엄마나 전문가들에게 적극적으로 상담을 구한 다 $(\mathrm{Z}=1.93)$ ', '나와 가족의 노력으로 내 아이는 지금보다 나아질 것 이다 $(\mathrm{Z}=1.89)$ '에 가장 긍정하고 있다. 반면 '나 때문에 내 아이의 문제가 생긴 것 같다 $(\mathrm{Z}=-1.99)$ ', '아이에게 드는 언어치료 비용이 너무 많다 $(\mathrm{Z}=-1.97)^{\prime}$ 에 가장 강하게 반대하고 있다.

제 1 유형에서 가장 높은 인자가중치 2.09 를 보인 16 번 대상자는 7 세 지적장애를 가진 여아의 어머니로 진단은 36 개월경에 받았고, 어머니가 느끼는 아동의 장애수준은 보통 정도라고 답하였다. 이 대상자는 아이의 언어 문제에 대해 주변 지인이나 전문가들에게 적극적으로 상담을 구한다고 하였는데, 아무리 머릿속으로는 다 아는 것도 실제로 적용하려면 어렵기 때문이라고 하였다. 또한 자 신의 처지를 터놓고 의논할 상대가 없어 힘들다는 것에 반대하였는 
Table 4. Example statements for each type

\begin{tabular}{|c|c|c|c|}
\hline Type & Statement & No. & Z score \\
\hline 1 & $\begin{array}{l}\text { Statements in the 'most important zone' } \\
\text { I ask advice from professionals or other mothers about my child's language problems. } \\
\text { If my family and I do our best, my child will get better. } \\
\text { My family can move for my child's language therapy. } \\
\text { Statements in the 'least important zone' } \\
\text { I suffer from other family members who meddle in my child's language therapy. } \\
\text { It is hard for me to have no one to share my situation. } \\
\text { My child does not make eye contact. } \\
\text { The language therapy for my child costs too much. } \\
\text { I feel guilty about my child's problem. }\end{array}$ & $\begin{array}{l}71 \\
56 \\
22 \\
63 \\
62\end{array}$ & $\begin{array}{l}-1.57 \\
-1.81 \\
-1.89 \\
-1.97 \\
-1.99\end{array}$ \\
\hline 2 & $\begin{array}{l}\text { Statements in the 'most important zone' } \\
\text { It is hard for me to have no one to share my situation. } \\
\text { I suffer from other family members who meddle in my child's language therapy. } \\
\text { I feel guilty about my child's problem. } \\
\text { The language therapy for my child is too costly. } \\
\text { I am skeptical of the therapy's effectiveness even though I have been using the service for years. } \\
\text { I completely understand my child's language problem. } \\
\text { I do not fully agree with my child's diagnosis. } \\
\text { Statements in the 'least important zone' } \\
\text { My family can move for my child's language therapy. } \\
\text { If my family and I do our best, my child will get better. } \\
\text { My child is perfect except for his/her language problem. }\end{array}$ & $\begin{array}{l}56 \\
71 \\
62 \\
63 \\
70 \\
68 \\
67\end{array}$ & $\begin{array}{l}2.04 \\
1.98 \\
1.97 \\
1.86 \\
1.83 \\
1.76 \\
1.45\end{array}$ \\
\hline 3 & $\begin{array}{l}\text { Statements in the 'most important zone' } \\
\text { I want to use smartphone applications for my child's communication improvement. } \\
\text { I hope for the development of more TV program contents related to my child's communication improvement. } \\
\text { I wish there were more rental services providing materials (e.g., DVD, books) for my child's communication development. } \\
\text { I'd like to participate in a language therapy program using a robot. } \\
\text { I'd like to use a tablet PC in language therapy sessions. } \\
\text { My child is not able to interpret facial expressions or tones. } \\
\text { My child does not use gestures appropriately. } \\
\text { Statements in the 'least important zone' } \\
\text { I consider distance when choosing a language therapy service. } \\
\text { I do not fully agree with my child's diagnosis. } \\
\text { I do not want an official disability diagnosis although I am fully aware of my child's problem. } \\
\text { I am skeptical of the therapy's effectiveness even though I have been using the service for years. } \\
\text { My child engages in much physical contact. }\end{array}$ & $\begin{array}{l}51 \\
47 \\
50 \\
48 \\
49 \\
23 \\
24\end{array}$ & $\begin{array}{l}2.21 \\
1.96 \\
1.93 \\
1.80 \\
1.79 \\
1.52 \\
1.28\end{array}$ \\
\hline
\end{tabular}

데, 주변에 아이의 문제를 터놓고 의논할 엄마들이 많기 때문이라 고하였다.

인자가중치가 2.08 인 1 번 대상자는 8 세 지적장애를 가진 남아의 어머니로 진단은 28 개월경에 받았고, 어머니가 느끼는 아동의 장 애수준은 경하다고 답하였다. 이 대상자는 가족들과 함께 최선을 다하고 있기 때문에 언젠가 반드시 좋아질 것이고, 아이가 받는 언 어치료 과정을 지켜보면서 그 스킬을 배우고 집에서도 적용해 보고 싶다고 하였다. 반면 이 대상자는 부모 상담시간을 치료시간으로 채우기 보다는 오히려 궁금한 점을 물어볼 수 있도록 전문가와의 상담시간이 늘어나기를 바랐다.

즉, 제 1 유형에 속한 대상자들은 전반적으로 아동의 장애 정도나 예후에 대해 긍정적인 경향성을 띠고 있으며 불만 섞인 요구를 표 현하지 않고 아이의 장애에 대한 수용이 넓은 것으로 나타났다. 이
상의 결과를 종합하여 제 1 유형을 ‘외적 소통형’이라고 명명하였다.

\section{제2유형: 내적 분석형}

제 2 유형으로 분류된 참가자는 8 명으로, 인구사회학적 특성은 Table 2 와 같다. 제 2 유형으로 분류된 참가자의 아동의 진단명은 지 적장애 1 명, 자폐성아동 7 명이었으며, 그들 중 6 명은 아동의 장애수 준이 심한 편이라고 응답하였다.

제 2 유형이 크게 동의하거나 부정하는 진술문과 그 비중을 제시 하면 Table 4 와 같다. 제 2 유형에 속한 대상자들은 아이가 '나는 내 처지를 터놓고 의논할 상대가 없어 힘들다 $(\mathrm{Z}=2.04)$ ', '나 때문에 내 아이의 문제가 생긴 것 같다 $(\mathrm{Z}=1.98)$ '에 가장 긍정적인 동의를 보 였다. 반면, '내 아이는 언어적인 어려움만 제외하면 완벽하다 $(\mathrm{Z}=$ -2.08)'와 '나와 가족의 노력으로 내 아이는 지금보다 나아질 것이 
다 $(\mathrm{Z}=-2.03)^{\prime}$ 에 강한 부정을 보였다.

제 2 유형에서 가장 높은 인자가중치 4.23 을 나타낸 12 번 대상자 는 9세 자폐성장애를 가진 남아의 어머니로 진단 시점은 36 개월이 며 어머니가 느끼는 아동의 장애수준은 매우 심한 것으로 나타났 다. 이 대상자는 언어치료의 효과를 느끼지 못하지만 안 받으면 불 안하니까 받고는 있으나 그 비용이 부담스러우며, 자신 때문에 아 이의 문제가 생긴 것 같아서 괴롭다고 하였다. 반면 형편상 아이의 언어치료를 위해서 쉽게 이사를 다닐 수는 없으며, 정확한 언어진 단을 받으면 더 절망스러울까 봐 두렵다고 하였다.

그리고 인자가중치 2.97 을 보인 13 번 대상자는 8 세 자폐성장애 를 가진 여아의 어머니로 진단은 35 개월경에 받았고 어머니가 느끼 는 아동의 장애수준은 심하다고 나타났다. 이 대상자는 자신의 가 족 모두 심하게 간섭하는 것이 지겹고, 모든 것이 자신의 탓이라는 생각이 든다고 하였다. 또한 아이가 언어문제 때문이 아니라 다른 문제가 있기 때문에 학교생활이 어려운 것이고, 예전에는 노력하면 아이가 나아질 것이라고 생각했지만 지금은 그렇게 생각하지 않는 다고 하였다.

즉 제 2 유형에 속한 대상자들의 경우 표면에 드러나는 성향으로 는 매사에 부정적인 경향성을 띠고 있으며, 아동의 장애 정도를 심 하게 판단하여 좋지 않은 예후를 가지고 있다고 생각하였다. 또한 사회에 대한 불만과 요구사항이 많지만 그에 대한 극복의지는 약 하며, 다른 사람과 소통하여 해답을 찾기보다는 문제를 회피하거 나 자신의 탓으로 돌리며 자책하는 등의 양상을 보이는 등 극복 의 지에서도 약한 유형이었다. 이상의 결과를 종합하여 제 2 유형을 '내 적 분석형'이라고 명명하였다.

\section{제3유형: 매체 탐험형}

제 3 유형으로 분류된 참가자는 4 명으로, 인구사회학적 특성은 Table 2과 같다. 제 3 유형으로 분류된 참가자의 아동의 진단명은 모 두 자폐성아동 4 명이었으며, 그들은 아동의 장애수준이 보통 또는 가벼운 편이라고 응답하였다.

제3유형이 크게 동의하거나 부정하는 진술문과 그 비중을 제시 하면 Table 4 와같다.

제 3 유형에 속한 참가자들이 적극 찬성한 항목은 ‘의사소통 증진 을 위해 다양한 스마트폰 어플을 사용하길 바란다 $(\mathrm{Z}=2.21)$ ', 'TV 방송 프로그램에 의사소통 관련 콘텐츠가 개발되었으면 좋겠다 $(\mathrm{Z}=1.96)$ '는 것이다. 반면 '내 아이는 과도한 신체 접촉을 한다 $(\mathrm{Z}=$ -1.91)'와 '언어치료의 효과를 기대하진 않지만 꾸준히 받고 있다 $(\mathrm{Z}=-1.79)^{\prime}$ 에 강한 부정을 하였다.

제 3 유형에서 가장 높은 인자가중치 2.64 를 보인 20 번 대상자는
10 세 자폐성장애를 가진 여아의 어머니로 48 개월경에 진단을 받았 다고 하며 어머니가 느끼는 아동의 장애수준은 경하다고 답하였 다. 이 대상자는 아이가 스마트폰을 좋아하지만 현재는 게임만 하 는데 의사소통을 증진시켜주는 어플리케이션이 있으면 좋을 것 같 고, TV도 같은 만화라도 언어를 늘려주는 만화라면 좋겠다고 하였 다. 또한 경력이 오래된 언어치료사에게 치료를 받은 경험이 있는데 오히려 틀에 박힌 느낌이었다고 하였다.

인자가중치 2.51을 보인 22번 대상자는 6세 자폐성장애를 가진 남아의 어머니로 진단은 34 개월경에 받았고 어머니가 느끼는 아동 의 장애수준은 경하다고 답하였다. 이 대상자의 경우 매번 책 같은 것을 사서 보여주면 부담이 되는데 쉽게 대여가 가능하다면 도움 이 될 것 같다고 하였다. 또한 아이가 로봇을 좋아하는데 이것을 이 용한 언어치료 프로그램이 있다면 아이가 좋아할 것이라고 하였다. 제3유형의 경우 스마트폰/태블릿PC 어플리케이션이나 로봇 등 의 다양한 매체를 원하는 호기심이 강한 유형으로 나타났다. 이상 의 결과를 종합하여 제 3 유형을 ‘매체 탐험형'이라고 명명하였다.

\section{논의 및 결론}

본 연구에서는 발달장애아동의 어머니들이 인식하는 자녀의 의 사소통 문제 및 이와 관련된 요구의 유형 및 특성에 관한 주관적 구 조를 분석하고자 하였다.

제 1 유형인 ‘외적 소통형'의 어머니들은 아이의 증상이 대체로 가 벼운 편이라고 여기며, 이에 따라 치료적 예후를 긍정적으로 평가 하는 것으로 나타났다. 따라서 아이가 호전될 것이라는 희망을 가 지고 아이에게 필요한 정보를 얻기 위하여 전문가와 주변으로부터 도움을 받고자 하는 등 매우 적극적인 성향을 보였다. 이는 자녀의 장애진단에 충격을 받은 부모가 1차적으로는 사실을 부인하고 두 려움과 좌절감을 느끼지만 결국 자녀의 장애를 인정하고 수용함으 로써 가정의 일상사와 자녀를 위한 교육활동에 적극적으로 참여하 게 된다고 하는 Turnbull과 Turnbull (2001)과 Koo와 Lee (2002)의 연구결과와 일치한다.

또한 이들은 아이의 문제는 하늘의 뜻이라 생각하고 스트레스 를 받지 않으며 가족 모두 언어치료의 효과를 기대한다고 하였다. 이는 모든 장애아동의 가족이 자녀의 장애로 인해 부정적인 경험 만을 하는 것은 아니며, 실제로 많은 가족들이 자녀의 장애에 성공 적으로 적응하고 있고(Bristol, Gallagher, \& Schopler, 1988), 양육 자들이 양육 경험의 일부로서 스트레스뿐만 아니라 전반적으로 보 상과 만족감을 갖게 된다(Grant, Ramcharan, McGrath, Nolan, \& Keady, 1998)고 보고한 연구결과와 일치함을 알 수 있다. 반면 제1 
유형의 어머니 그룹의 학력은 높지 않았는데, 이는 부모의 교육수 준이 높을수록 장애아 양육에 필요한 정보와 서비스를 쉽게 얻을 수 있기 때문에 정서 스트레스를 적게 느낀다고 보고한 선행연구 (Seo, 1992)와는 다른 결과를 보였다.

제 2 유형인 '내적 분석형'에 속하는 어머니들은 아이의 증상을 대 체로 심한 편이라고 생각하며, 그에 대한 예후에도 부정적인 시각 을 가지고 있는 것으로 나타났다. 또한 전반적으로 아이의 장애 원 인을 본인의 탓으로 돌리며 자책하는 경향이 많았고, 이로 인해 아 동에 대해 타인과 소통하는 것을 회피하는 등 가족 및 지인들의 간 섭이 심한 것에 스트레스를 호소하였으나 반면에 아이의 문제에 대 해 의논할 상대가 없다는 것에 대해서도 어려움을 호소하는 이중 적인 심리상태를 나타냈다. 이는 제 2 유형에 속한 어머니의 아동이 대부분 자폐성아동이라는 점에 주목해보았을 때, $\operatorname{Sim}$ (1984)의 연 구에서 자폐성아동의 어머니가 자신의 역할 부족이나 정서적인 고 통 때문에 자녀가 자폐아가 된 것으로 간주하고 초기에 장애를 알 아채지 못한 것에 대한 죄책감을 갖는다고 한 연구 결과를 지지한 다. Holroyd와 McArthur (1976)는 다른 장애아 부모보다 자폐아의 어머니들이 자녀에게 더 크게 당혹해하고 실망하여, 자녀의 의존성 을 인식하고 크게 우려했으며 그 아동이 나머지 가족에게 미치는 영향, 장래의 직업문제, 아동의 인성, 행동문제를 더 많이 인식하고 있다고 하였다.

이와 함께 이 유형의 대상자들 대부분이 자녀의 언어치료에 들 어가는 비용에 부담을 느끼는 것으로 나타났다. 다수의 선행연구들 (Choi, 1986; Gallagher, Beckman, \& Cross, 1983; No, 2001; Wing, 1976)이 장애아 가족이 겪고 있는 문제점으로 경제적 문제를 꼽고 있는데 장애 아동은 어릴 때부터 특별한 치료와 교육을 받아야 하 고 그 기간이 단기로 끝나지 않기 때문이다. Gallagher 등(1983)의 연구에서도 장애아 가족은 경제적 문제를 그들이 경험하는 큰 어 려움 중의 하나라고 지적하였고, 수입이 많을수록 거부감, 죄책감, 수치심과 같은 부정적인 태도가 적게 나타난다고 보았다(Choi, 1986). 특히 자폐성아동의 부모는 다른 장애와는 다르게 자녀가 성 장해도 문제행동이 나아지는 경우가 드물어 자녀의 미래에 대한 염 려 및 치료에 들어가는 경제적 부담이 크다고 하였다(Wing, 1976). 실제로 본 연구에서 내적 분석형에 속한 8 명의 어머니 중 4 명이 아 이의 언어치료 비용을 개인이 부담하고 있는 것으로 나타나, 외적 소통형에 속한 12 명의 어머니 중 10 명이 보험, 회사, 학교, 지자체 등 에서 다양한 지원을 받고 있는 것과 대조되었다.

제 3 유형의 '매체 탐구형' 어머니들은 스마트폰, 태블릿PC, 로봇 등 다양한 매체를 사용하여 아동의 의사소통에 도움을 주기를 원 하였다. 이들 유형에 속하는 4 명의 대상자는 모두 자폐성장애 아동
의 어머니인 것으로 나타났는데, 이는 매체를 이용한 대부분의 연 구에서 타인에게 관심을 보이지 않는 자폐성아동에게 매체를 활용 하였을 때 효과적일 수 있다는 연구결과를 지지한다. 예를 들어, Kwon, Park, Yim과 Lee (2012)는 스마트폰, 태블릿PC를 포함한 스 마트 기기가 자폐성장애 아동의 삶을 지원하는 효율적인 도구로서 의 잠재력을 강조하면서 그러한 요인으로 예측 가능한 반응, 휴대 의 용이성, 높은 사용성, 앱의 다양성, 개별성과 개인성, 비주얼 디 스플레이, 그리고 문화적 수용성의 여섯 가지 요소를 들었다. 또한 스마트기기의 경우 아동이 스스로 조작하여야 하고, 이에 따라 즉 각적이고 구체적인 피드백이 제공되며, 그래픽이나 애니메이션, 음 향 등의 멀티미디어 요소로 인해 유아의 흥미와 주의집중을 끄는 특징이 있다(Han \& Hyun, 2008)고 하였다. 스마트기기의 어플리 케이션은 다른 콘텐츠와는 다르게 장시간을 요하지 않고 이동 중 이거나 잠깐의 시간을 사용하여 빠르고 쉽게 이용할 수 있다는 것 이 큰 특징이며(Lee, 2011), 이것은 자폐성 장애아동에게 효과적인 교육과 훈련을 위한 도구로서 스마트 매체의 가능성을 보여준다. 또한 이 유형에 속한 어머니들은 자신의 자녀들이 좋아하는 로봇 으로 언어치료를 한다면 더욱 효과적일 것 같다는 의견을 제시하 였다. 이는 지능형 교육 서비스 로봇을 이용한 교육적 효과가 입증 되면서 다수의 어린이집과 유치원에서 로봇을 이용하고 있는 현실 을 뒷밤침 해준다(Espinosa, Laffey, Whittaker, \& Sheng, 2006). 국 내에서도 교육 서비스 로봇의 개발이 활성화 되면서, 로봇을 교육 콘텐츠 전달 미디어로 사용하여 보조교사나 친구의 역할을 하게 하는 시도가 활발히 이루어지게 되었다. 로봇을 이용한 자폐아의 사회적 상호작용에 관한 중재 연구(Hong et al., 2010)는 자폐아들 이 로봇과의 상호작용 빈도수와 상호작용 지속시간이 증가하여 높 은 상호작용을 이끌어 내는데 성공했다고 보고하고 있다.

이상에서 살펴본 바와 같이 발달장애아동 어머니들은 장애아동 을 양육하면서 긍정적인 정서와 부정적인 정서가 복잡하게 얽힌 독 특한 심리적응 상태를 경험한다. 따라서 장애아 어머니들 각자의 독특한 특성과 요구에 대한 바른 이해를 토대로 그들에게 필요로 하는 지원이 무엇인지 파악하여 그들의 요구에 따른 지원이 이루어 지도록 해야 할 것이다.

이에 따라 각 유형별로 언어치료사의 역할을 제언해 보면 다음과 같다.

언어치료사는 제 1 유형의 외적 소통형 어머니들의 긍정적인 태도 와 열의를 격려하고 북돋아 줄 필요가 있다. 또한 어머니의 희생과 노력이 자녀의 장애 상태에 대한 비현실적인 신념이나 왜곡된 지각 으로 인한 것이 아닌지 정확하게 확인하고 객관적인 정보를 제공해 야 한다. 특히 어머니가 과한 열정으로 단기간의 과도한 에너지를 
Eun Jung Choi, et al. • Q Analysis of Mothers' Perspectives on Their Children with Developmental Disabilities

쏟아 부음으로 인해 쉽게 지치지 않도록 지지하여 꾸준히 노력할 수 있도록 도와야 한다. 이를 위해 아동의 어머니뿐만 아니라 다른 가족, 즉 배우자, 조부모, 아동의 형제자매의 관심과 참여 그리고 지 지가 필수적이다.

제 2 유형의 어머니는 현실과 이상의 경계가 모호하여 갈등이 많 은 그룹으로 판단되고 자신에 대한 분노나 우울 같은 부정적인 정 서 상태에 휩싸이기 쉬운 그룹으로 나타났다. 따라서 언어치료사 는 어머니에게 신뢰감을 심어주어 믿을만한 존재로 인식되는 것이 급선무이고, 어머니 자신의 부정적 정서를 통제하는데 초점을 맞추 어 도와야 한다. 또한 어머니의 냉담한 태도와 분노의 감정, 그리고 절망감에 대해 공감하고 이에 대한 정서적 지원을 해야 할 것이다.

마지막으로 적극적이고 진취적 성향을 가지고 있는 제 3 유형의 경우 이러한 장점을 최대한 활용하여 자녀를 위한 치료교육의 목 표와 내용, 그리고 앞으로의 방향을 모색하는 과정에 어머니의 참 여를 유도하는 것이 바람직하다.

본 연구에서는 발달장애 아동 어머니들이 느끼고 있는 자녀의 의사소통 문제를 파악하고, 어머니들이 갖는 문제 인식 유형과 지 원 요구의 형태를 세 가지 외적 소통형, 내적 분석형, 매체 탐구형으 로 유형화 하였다. 또한 이러한 세 가지의 유형은 고정된 것이 아니 라 이들이 처한 환경이나 상황과의 상호작용을 통해 지속적으로 변화될 수 있으므로 이를 토대로 어머니를 이해하며 바람직한 방 향으로 변화, 증진시키기 위한 참조의 틀을 제시하였다.

부모의 심리적 스트레스가 심할수록 다른 일상적 생활의 질적인 측면에도 나쁜 영향을 미칠 수 있음을 고려할 때, 부모들에게 기본 적으로 자녀의 장애상태를 심리적으로 인정할 수 있게 하고 현재 의 부정적인 상황을 긍정적으로 수용할 수 있는 사회적 지지체계 가 필요하다는 점은 분명하다. 예를 들어, 장애아 부모의 심리적 스 트레스 해소에 도움을 줄 수 있는 부모 상담센터 같은 시설을 활성 화시켜서 부모가 자신의 고민과 자녀의 장래에 대해 정기적으로 상 담할 수 있게 하고, 부모 역량 강화를 위한 부모교육 프로그램을 개 발하여 참여할 수 있는 기회를 제공하는 것도 좋은 방편이 되리라 생각된다.

\section{REFERENCES}

Bae, H. (2009). A study of stress factors of mothers having children with autism spectrum disorders and the mothers' ways to cope with the stress factors. Journal of Special Education: Theory and Practice, 10, 137-157.

Bishop, D. V. (1998). Development of the Children's Communication Checklist (CCC): a method for assessing qualitative aspects of communicative impairment in children. Journal of Child Psychology and Psychiatry, 39, 879891.

Bristol, M. M., Gallagher, J. J., \& Schopler, E. (1988). Mothers and fathers of young developmentally disabled and nondisabled boys: adaptation and spousal support. Developmental Psychology, 24, 441-451.

Bronfenbrenner, U. (1977). Toward an experimental ecology of human development. American Psychologist, 32, 513-531.

Choi, E. J. (1986). Study on the characteristics and the marital adjustment of the autistic children's parents (Master's thesis). Ewha Womans University, Seoul, Korea.

Choi, J. S., \& Lee, M. H. (2005). A study on parenting stress with disabled children and the quality of life. Journal of Korean Academy of Occupational Therapy, 13, 43-50.

Espinosa, L. M., Laffey, J. M., Whittaker, T., \& Sheng, Y. (2006). Technology in the home and the achievement of young children: findings from the early childhood longitudinal study. Early Education and Development, 17, 421-441.

Gallagher, J. J., Beckman, P. J., \& Cross, A. H. (1983). Families of handicapped children: Sources of stress and its amelioration. Exceptional Children, 50, 10-19.

Granlund, M., BjÖrck-ÅKesson, E., Wilder, J., \& Ylvén, R. (2008). AAC interventions for children in a family environment: implementing evidence in practice. Augmentative and Alternative Communication, 24, 207-219.

Grant, G., Ramcharan, P., McGrath, M., Nolan, M., \& Keady, J. (1998). Rewards and gratifications among family caregivers: towards a refined model of caring and coping. Journal of Intellectual Disability Research, 42, 58-71.

Ha, H. Y. (2010). A study of Nurturing attitude, stress, psychological security of mothers of language-disordered children (Master's thesis). Korea University, Seoul, Korea.

Han, Y. M., \& Hyun, E. J. (2008). Verbal and nonverbal behaviors of 2-yearold infants when reading a picture book alone or with peers. Journal of Human Life Science, 11, 111-124.

Holroyd, J., \& McArthur, D. (1976). Mental retardation and stress on the parents: a contrast between Down's syndrome and childhood autism. American Journal of Mental Deficiency, 80, 431-436.

Hong, J. W., Kim, Y. D., Kang, W. S., Lee, H. S., Baek, S. S., Ku, H. J., ... An, J. U. (2010). Experimental research of interactions between children with autism and robots. Journal of Emotional, Behavioral Disabilities, 26, 141168.

Jeon, G. O., Kang, D. O., \& Park, J. K. (2012). A study on actual conditions and 
parental perceptions in providing therapeutic support services for children with disabilities in Busan. Research of Special Education Children, 14, 211235.

Kim, H. K. (2008). Q methodology: philosophy, theories, analysis, and application. Seoul: Communication Books.

Kim, J. Y., Lee, K. J., Kim, E. S., Kim, J. H., \& Park, J. Y. (2005). Difficulties and support needs perceived by the families of children with communication disorders: a qualitative inquiry. Korean Journal of Communication Disorders, $10,58-81$.

Kim, Y. T. (2002). Assessment and treatment of language disorders in children. Seoul: Hakjisa.

Koo, M. H., \& Lee, Y. H. (2002). Ideal maternal behaviors as viewed by professionals in three different cultures: Korea, the United States and France. Korean Journal of Child Studies, 23, 89-105.

Kwon, J. M., Park, E. H., Yim, J. H., \& Lee, Y. J. (2012). Proposal for mobile application and game for persons with autism. Korean Journal of Computer Game Studies, 25, 31-42.

Lee, H. J., Kang, M. K., \& Kim, Y. T. (2013). Current practice and support needs in smart media perceived by the mothers of children with communication difficulties. Communication Sciences \& Disorders, 18, 163-171.

Lee, H. W., Kang, W. Y., \& Lee, S. B. (1999). A characteristic relationships study of rearing attitude and parenting stress of parents of children with disabilities. Journal of Special Education, 22, 99-117.

Lee, J. Y. (2011). Study on the parental perceptions of educational smartphone applications (Master's thesis). Kyung Hee University, Seoul, Korea.
Lee, M. S., \& Kim, K. J. (2000). Strategies for supporting families of infants and preschoolers with disabilities. Asan: Korea Institute for Special Education.

Lee, S. H. (2000). Facilitating family involvement in special education. Korean Journal of Communication Disorders, 5, 174-191.

No, H. R. (2001). Study of needs of families with cerebral palsied children participating in physical therapy intervention (Master's thesis). Daegu University, Daegu, Korea.

O'Shea, D. J. (2001). Families and teachers of individuals with disabilities: collaborative orientations and responsive practices. Boston, MA: Allyn \& Bacon.

Oh, S. J., Lee, E. J., \& Kim, Y. T. (2012). Preliminary study on developing test items of children's pragmatic language checklist. Journal of Speech \& Hearing Disorders, 21, 111-135.

Robbins, F. R., Dunlap, G., \& Plienis, A. J. (1991). Family characteristics, family training, and the progress of young children with autism. Journal of Early Intervention, 15, 173-184.

Seo, H. Y. (1992). Study of the adjustment and social supports of mothers of disabled children (Master's thesis). Yonsei University, Seoul, Korea.

Sim, S. H. (1984). Study of characteristic in mothers of children with PDD (Master's thesis). Sookmyung Women's University, Seoul, Korea,

Turnbull, A. P., \& Turnbull, H. R. (2001). Families, professionals, and exceptionality: collaborating for empowerment. Upper Saddle River, NJ: Prentice Hall.

Wing, L. (1976). Epidemiology and theories of aetiology. Early Childhood Autism, 65-92. 


\section{국문초록}

\section{발달장애 어머니의 자녀 의사소통 문제 인식 및 지원요구에 관한 Q방법론적 연구: 자폐성장애 및 지적장애를 중심으로}

최은정 · 김영태 · 강민경 · 이현정

이화여자대학교 언어병리학과

배경 및 목적: 본 연구에서는 주관적 요인을 분석하는 Q방법론을 통하여 자녀의 의사소통 어려움 및 지원요구에 대한 발달장애아동 어머니의 인식 및 그 유형의 특성을 고찰하고자 하였다. 방법: $\mathrm{Q}$ 방법론을 적용하여 발달장애아동을 둔 어머니가 인식하는 자녀의 의사 소통 어려움과 요구에 대한 72 개의 Q진술문을 24 명의 대상자에게 적용하여 자료를 수집하였고, 이를 QUANL 프로그램을 이용하여 처리하였다. 결과: 발달장애 자녀의 의사소통 어려움에 대한 어머니의 인식유형을 분석한 결과, 각기 독특한 특성을 가진 3 개의 유형이 나타났다. 제 1 유형은 '외적 소통형'으로 전반적으로 긍정적인 경향성을 띠고 있으며 아이의 장애에 대한 수용이 넓은 것으로 나타났다. 제 2 유형은 ‘내적 분석형'으로 표면적으로 부정적인 경향성을 띠고 있으며 극복의지 면에서도 약한 유형이었다. 마지막으로 제 3 유형은 '매체 탐험형'으로 스마트기기, 로봇 등 다양한 매체를 원하는 것으로 나타났다. 논의 및 결론: 본 연구의 결과의 결과를 통하여 언어치 료사 및 관련 전문가들이 의사소통장애 아동과 그 가족이 느끼는 어려움을 점검하고 어떠한 부분에 중점을 두어 서비스를 제공할 것 인가를 논의하였다.

핵심어: 발달장애아동, 의사소통 문제, 어머니 인식, Q방법론

이 논문은 제 1 저자의 2013년 석사학위논문을 수정 보완한 논문임.

이 논문은 2012년 정부(교육부)의 재원으로 한국연구재단의 지원을 받아수행된 연구임(NRF-2012S1A5A2A03034254).

\section{참고문헌}

구미향, 이양희(2002). 한·미·불 전문가의 시각에서 본 영아기 이상적인 모성행동. 아동학회지, 23, 89-105.

권정민, 박은혜, 임장현, 이영지(2012). 자폐성 장애인을 위한 기능성 모바일 앱 및 게임 제안서. 한국컴퓨터게임학회논문지, 25, 31-42. 김영태(2002). 아동언어장애의 진단 및 치료. 서울: 학지사.

김정연, 이금진, 김은숙, 김주혜, 박지연(2005). 의사소통 장애아동을 둔 가족의 어려움과 지원요구에 관한 질적 연구 언어청각장애연구, 10, 58-81. 김흥규(2008).Q 방법론: 과학철학, 이론, 분석 그리고 적용, 서울: 커뮤니케이션북스.

노효련(2001). 물리치료 대상 뇌성마비아가족의 요구조사. 대구대학교 재활과학대학원 석사학위논문.

배혜영(2009). 자폐범주성장애아동 어머니의 스트레스 요인과 해결방안에 대한 연구. 특수교육저널, 10, 137-157.

서혜영(1992). 장애아어머니의 적응과사회적 지원에 관한 연구. 연세대학교대학원 석사학위논문.

심숙희(1984). 전반적 발달장애 아동 어머니의 성격특성연구. 숙명여자대학교대학원 석사학위논문.

오소정, 이은주, 김영태(2012). 화용능력 체크리스트 문항 개발을 위한 예비 연구. 언어치료연구, 21, 111-135.

이미선, 김경진(2000). 장애영유아가족지원 방안연구. 아산: 국립특수교육원.

이소현(2000). 특수교육에 있어서의 바람직한 가족 참여를 위한 지원 및 중재방안 고찰. 언어청각장애연구, 5, 174-191.

이주연(2011). 유아교육용 스마트폰 앱에 대한 부모 인식 조사: 유아의 행동패턴에 따른 부모 인식 조사를 중심으로. 경희대학교 경영대학원 석사학 위논문.

이한우, 강위영, 이상복(1999). 장애아동 부모의 양육태도 및 스트레스간의 관계적 특성 연구. 특수교육연구, 22, 99-117.

이현정, 강민경, 김영태(2013). 어머니가 인식한 자녀의 의사소통 어려움과 스마트미디어 활용 현황 및 요구조사. 언어청각장애연구, 18, 164-171.

전귀옥, 강대옥, 박재국 (2012). 장애아동 치료지원서비스 이용 실태 및 부모의 인식-부산지역을 중심으로. 특수아동교육연구, 14, 211-235. 
최은정(1986). 자폐아동부모의 특성과 부부적응도에 관한 연구. 이화여자대학교 석사학위논문.

최정실, 이미희(2005). 장애유형별 부모의 양육스트레스와삶의 질에 관한 연구. 대한작업치료학회지, 13, 43-50.

하해영(2010). 언어장애아 부모들의 양육태도, 양육스트레스와 심리적 안녕감에 관한 연구. 고려대학교 석사학위논문.

한유미, 현은자(2008). 그림책보기 상황에서 나타나는 2세 영아 혼자, 또래간의 비언어적, 언어적 행동. 생활과학, 11, 111-124.

홍종욱, 김영덕, 강원석, 이효신, 백상수, 구현진, 안진웅(2010). 로봇과 자폐 아동의 상호작용에 관한 실험연구. 정서행동장애연구, 26, 141-168. 